\title{
$\operatorname{arCOS} D E S I G N$
}

\section{Um enfoque ergonômico sobre a metodologia de design de interfaces digitais para dispositivos móveis}

Adriana Chammas (PUC-Rio, Brasil)

ttdri@yahoo.com.br

Rua Marquês de São Vicente, 225, Gávea

Rio de Janeiro, RJ, Brasil, CEP: 22451-900

Manuela Quaresma (PUC-Rio, Brasil)

mquaresma@puc-rio.br

Cláudia Mont'Alvão (PUC-Rio, Brasil)

cmontalvao@puc-rio.br 


\title{
Um enfoque ergonômico sobre a metodologia de design de interfaces digitais para dispositivos móveis
}

Resumo: Esse artigo descreve as metodologias de projeto para sistemas interativos mais utilizadas hoje e questiona se a premência competitiva do mercado pode trazer obstáculos para a consideração do Design Centrado no Usuário no desenvolvimento de aplicativos para dispositivos móveis, uma vez que os desenvolvedores precisam entregar cada vez mais rápido seus produtos, ainda que submetidos a restrições orçamentárias, cronogramas limitados, características específicas de cada aplicativo, e ainda devem ouvir o usuário.

Palavras-chave: Usabilidade, Metodologia, Sistemas Interativos

\section{An ergonomic approach on the design methodology for mo- bile digital interfaces}

\begin{abstract}
This article describes the most used design methodologies nowadays and discuss whether the market competitive urgency can bring obstacles for User-Centered Design in applications development for mobile devices, once system developers need to deliver their products faster and faster, even under budget restrictions, limited time, different operational systems and different kind of apps, they still need to consider the user's voice.
\end{abstract}

Key words: Usability, Methodology, Interactive Systems 


\section{Introdução}

Os telefones celulares são utilizados por pessoas de todas as idades, das mais variadas culturas e backgrounds. Esses aparelhos antes utilizados para cumprir sua função básica (fazer ligações), hoje assumiram o lugar dos desktops (computadores de mesa) e dos laptops (computadores de colo) e se transformaram em smartphones poderosos que permitem o acesso a tudo e a todos, possibilitam transpor barreiras dantes inimagináveis - a qualquer hora e em qualquer lugar. Pela mobilidade, praticidade e possibilidades que fornecem, transformaram comportamentos e atitudes e se tornaram indispensáveis na vida de seus usuários.

Além de permitirem fazer ligações sem fio, os smartphones oferecem acesso à internet, email, serviços de mensagem e uma infinidade de opções de funções personalizáveis através de aplicativos dedicados, os apps. Os tablets também são considerados sistemas mobile assim como os smartphones, porém se diferem desses pelo tamanho, resolução de tela e por também permitirem fazer ligações convencionais, por Skype e/ou similares e por possibilitar inputs diretamente na tela, através do toque e/ou movimento dos dedos nela. Com sua fronteira cada vez menos perceptível, smartphones e tablets são usados para navegar tanto pelo mundo real quanto pelo virtual, moldar relações, consumir entretenimento e filtrar o que se quer. O limite entre os dois se mostrou tão tênue que o mercado os uniu e lançou os phablets.

De acordo com a pesquisa "The Mobile Consumer" publicada em fevereiro de 2013 pelo instituto de pesquisas Nielsen Holdings N.v. (2013), o uso dos smartphones no Brasil alcança 36\% dos brasileiros adultos entrevistados - todos usuários de internet. $\mathrm{O}$ fato de mais da metade desses brasileiros alegar não sair de casa sem ele, corrobora com Skeldon (2011) quando este coloca a ideia da gigante espanhola Telefónica, de que os smartphones são um "controle remoto para a vida", pode ser prematura, mas está longe de estar errada. Os smartphones mudaram o modo como os consumidores pesquisam por informações, como fazem compras e como se socializam. Os usuários de smartphones usam suas mídias para a realização de várias tarefas simultâneas (figura 1): $88 \%$ usam o telefone durante outras atividades, como ouvir música (63\%) e/ ou assistir TV (46\%).

Lindstrom (2010) ilustra esses resultados no livro "Brand Sense", ao comentar que comerciais de TV não atingem mais os consumidores, que somente os escutam enquanto praticam outras atividades, como fazer um café ou utilizar seus smartphones, por exemplo. O autor coloca que mesmo com o aumento médio de investimento ao ano em publicidade, a efetividade e a lembrança das campanhas de marca são cada vez menores, enquanto 94\% dos usuários de smartphones percebem anúncios para celular. 


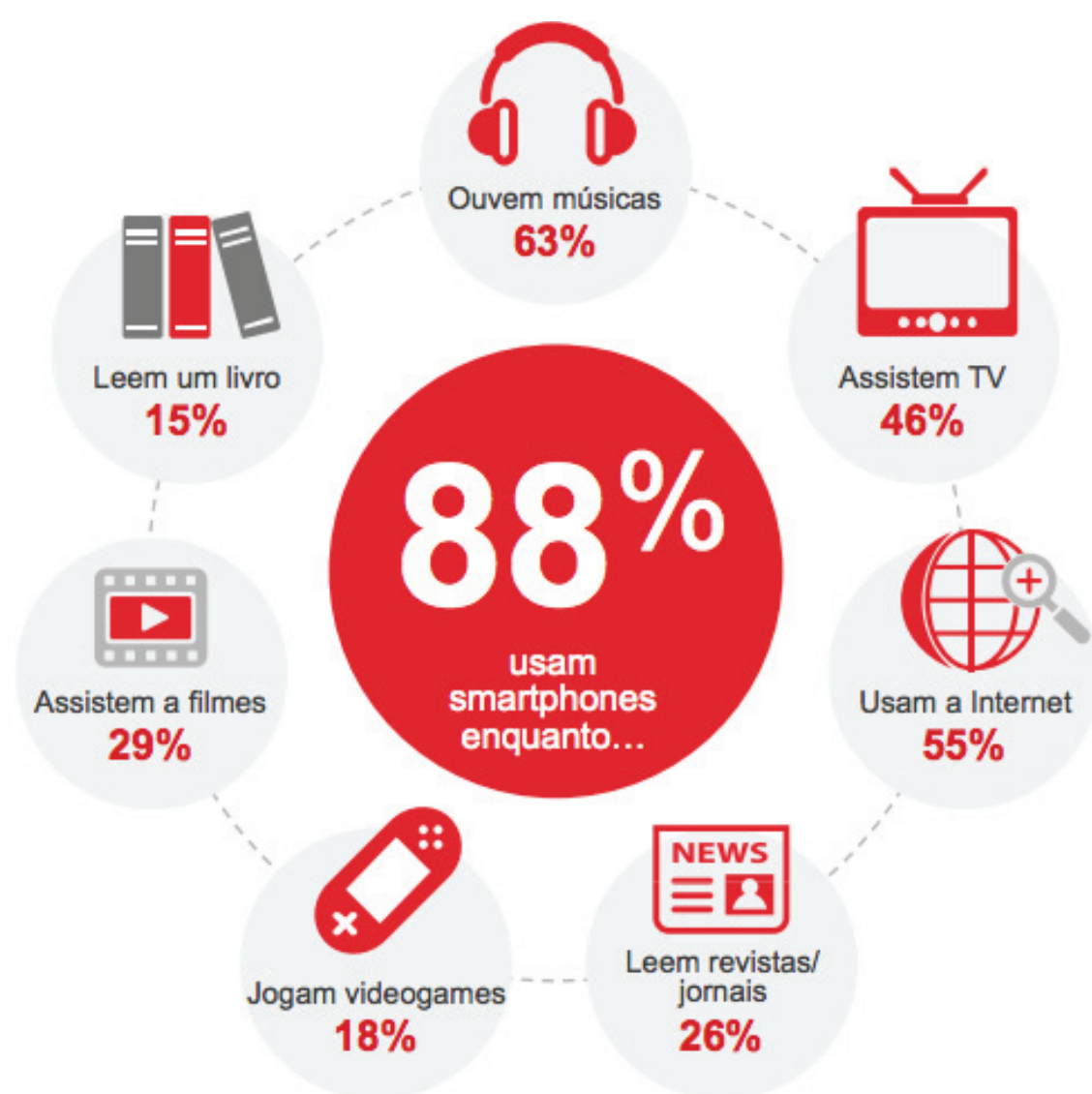

Figura 1. Percentual de atividades simultâneas dos usuários enquanto utilizam seus celulares. http://services.google.com/fh/files/blogs/our_mobile_planet_brazil_pt_BR.pdf (acesso em 21 de junho de 2013 às 9h).

Frente à notável importância de seus produtos, as empresas fabricantes de smartphones investem céleres no desenvolvimento de aplicativos que incrementem a produtividade da rotina de seus usuários e pluralizem as possibilidades de seus aparelhos.

\section{Apps, apps nativos e web-apps}

O mercado de smartphones atingiu a maturidade ao alcançar uma relativa homogeneidade de funcionalidades - em um processo de contínuo desenvolvimento tecnológico - respeitadas as diferenças de categorias no escopo do produto. O diferencial desse mercado são as opções de função personalizáveis de seus aplicativos, também chamados apps, que cada fabricante permite rodar em seu sistema operacional. 
Para ilustrar a relevância dos aplicativos para mobile no cotidiano dos usuários a pesquisa mundial feita pelo instituto Nielsen aponta o Brasil em segundo lugar (74\% dos usuários) no consumo de aplicativos para mobile, atrás da Coréia do Sul (81\%). Os tipos de aplicativos para mobile mais usados entre os brasileiros são: games (68\%), redes sociais (67\%), sistemas de orientação (mapas, navegação e busca) (51\%), filmes (49\%), notícias (45\%), tempo (37\%), instituições financeiras (36\%), compras (26\%) e produtividade (24\%), nessa ordem.

Os apps são aplicativos desenvolvidos para rodar em dispositivos mobile, disponíveis online e adequados ao sistema operacional do fabricante do dispositivo que se propõem a incrementar a produtividade do usuário. Entre os sistemas operacionais (os) para smartphones existentes, quatro destacam-se em termos de expressividade no mercado desses aplicativos, são eles: ios, Android, Windows Phone e Blackberry. Os sistemas operacionais diferem-se pela estrutura de navegação e pelo vínculo às lojas de aplicativos (app stores), a plataforma de distribuição digital desses aplicativos. Estas lojas disponibilizam o download imediato dos aplicativos, normalmente dispostos em categorias (entretenimento, produtividade, games etc) e obedecem às regras de comercialização dos fabricantes do aparelho e/ou do os. Não limitadas à comercialização, essas regras também abrangem conteúdo e qualidade desses aplicativos.

Existem basicamente dois tipos de aplicativos desenvolvidos para smartphones: os apps nativos e os web-apps. Os apps nativos são aplicativos dedicados a sistemas operacionais específicos, têm acesso irrestrito a recursos do sistema operacional do aparelho, bem como aos componentes do hardware (GPS, acelômetro e câmera), e oferecem uma rica experiência ao usuário. Os apps nativos precisam seguir um pacote de desenvolvimento de software específico do os para o qual estiver sendo desenvolvido, o SDK - Software Development Kit. Os SDKS são disponibilizados pelas fabricantes dos OSs para que os desenvolvedores se adequem a eles.

Já os web-apps são aplicativos que rodam exclusivamente em navegadores (browsers), funcionam de forma similar a sites versão mobile, têm acesso limitado ao hardware do sistema operacional e funcionam exclusivamente online. A decisão de desenvolver um ou outro, ou seja, nativo ou web-app, depende de fatores como objetivos do negócio, da audiência, dos requisitos técnicos entre outros. Pode-se conferir no exemplo abaixo as telas do Twitter para as versões de app nativo e web-app (figura 2), nessa ordem. 


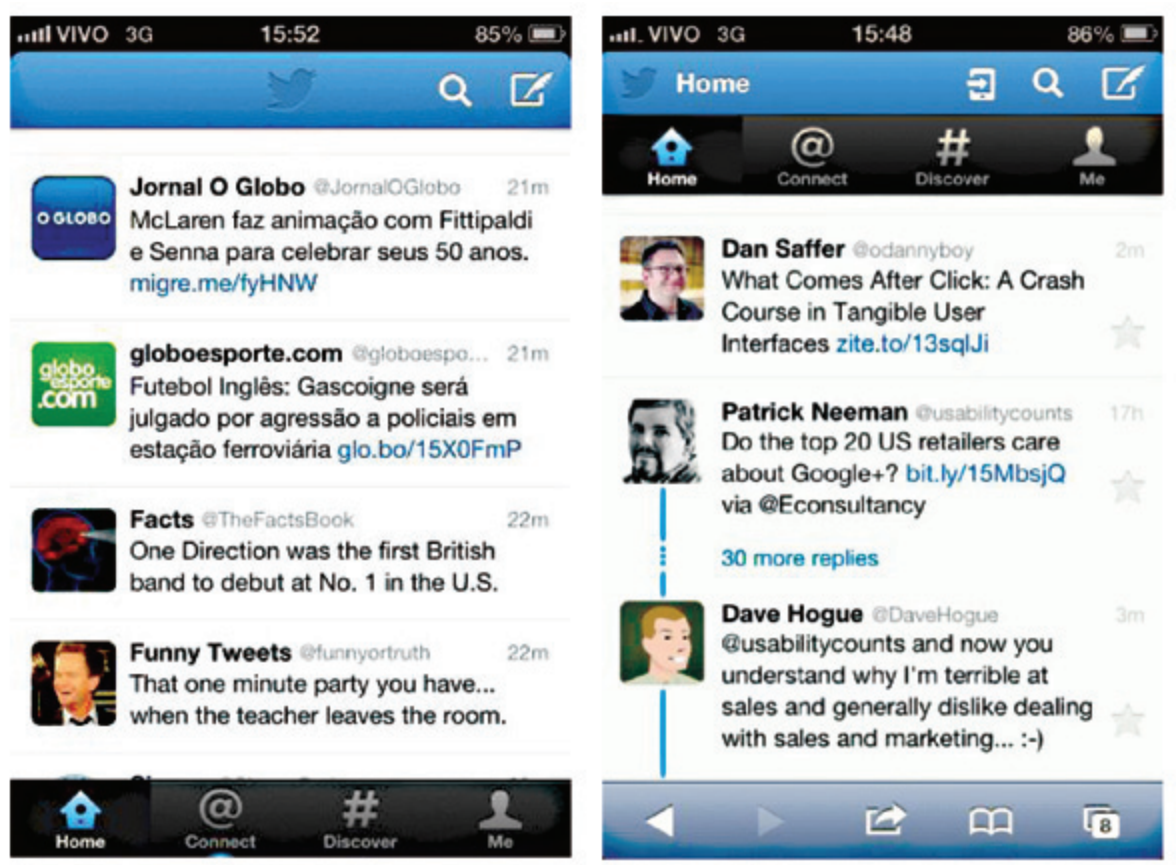

Figura 2. Telas do app nativo e do web-app do Twitter e as significativas diferenças entre elas.

Apesar das similaridades em algumas interações, os sistemas para mobile diferem em vários aspectos relacionados à estrutura e à navegação. Embora essas diferenças devam ser pontuadas, o mais importante é a preocupação que os desenvolvedores devem ter em adaptar as linhas de código, considerando todos os elementos que possam afetar a experiência holística do usuário.

Skeldon (2011) tem como situação ideal combinar as funcionalidades dos aplicativos nativos à conectividade dos web-apps. Wroblewski (2011) comenta em seu livro Mobile First que, se uma proposta de criar um aplicativo nativo para cada plataforma fosse cumprida, os custos de manutenção se tornariam proibitivos. Para driblar algumas das restrições técnicas dos diferentes OS, como o tamanho e a resolução das telas, por exemplo, os desenvolvedores têm se dedicado a criar soluções híbridas de web-apps, nas quais os elementos da arquitetura se apresentam de forma idêntica ao usuário independente da plataforma.

Com um mercado tão atraente é natural - e esperado - que as empresas desenvolvedoras de aplicativos precisem entregar cada vez mais rápido seu produto para os clientes e, por conseguinte, inseri-los nas apps stores. O balizador dessa engrenagem é o desafio dos desenvolvedores, que além de trabalhar sob restrições orçamentárias e temporais (cronogramas restritos), precisam ainda levar em conta os diferentes sistemas operacionais e as diferentes características de cada aplicativo, ou seja, se serão aplicativos nativos ou web-apps. 
A partir desse instigante cenário discutem-se quais metodologias são empregadas por essas empresas e por que foram escolhidas, como elas são aplicadas na prática, qual a opinião dos desenvolvedores sobre elas e, principalmente, quando entra a voz do usuário neste processo, ou seja, como é o envolvimento dele e em quais etapas. A ISO 9241-210/2010 descreve uma abordagem de desenvolvimento de sistemas interativos focada nos interesses e necessidades dos usuários, com a aplicação de critérios ergonômicos e conhecimentos e técnicas de usabilidade. Essa abordagem amplia a efetividade, melhora o bem estar humano, a acessibilidade e a sustentabilidade e leva em conta os diversos efeitos que esses sistemas interativos podem causar na saúde, segurança e desempenho do usuário.

A ISO 9241-210/2010 estabelece que uma metodologia de desenvolvimento de sistemas interativos deve seguir os seguintes princípios:

- O projeto deve ser baseado na compreensão explícita dos usuários, das tarefas e dos ambientes;

- Os usuários devem estar envolvidos em todo processo de desenvolvimento do projeto;

- O projeto deve ser orientado e refinado por avaliação centrada no usuário;

- O processo deve ser iterativo;

- O projeto deve abordar toda a experiência do usuário;

- A equipe deve ter competências e habilidades multidisciplinares.

Essa específica parte da ISO 9241-210/2010 complementa abordagens de sistemas existentes e pode ser incorporada a metodologias diversas apropriadas a contextos particulares. Embora não eleja nenhum processo de design em particular nem descreva todas as atividades necessárias para assegurar a efetividade do design do sistema, a ISO 9241-210/2010 é complementar às metodologias, de forma que seus parâmetros podem beneficiar todas as partes envolvidas em busca do melhor design de interfaces, o centrado no usuário.

\section{Metodologias e Processos de Desenvolvimento de Softwares}

Segundo Sommerville (2007) apud Melcher (2012) não existe um processo projetual ideal. As organizações desenvolvem abordagens adequadas ao desenvolvimento de seus softwares de acordo com seu modelo próprio e o grau de estruturação varia de acordo com a criticidade do sistema. "Em sistemas de negócios, com requisitos que mudam rapidamente, um processo flexível e ágil é provavelmente mais eficaz" (Sommerville, 2007 apud Melcher, 2012). A autora complementa que o modelo de engenharia de software deve ser escolhido 
com base na natureza dos projetos e que diferentes tipos de sistema requerem diferentes processos de desenvolvimento.

Dentre as muitas metodologias existentes para desenvolvimento de sistemas interativos e dos prós e contras de cada uma delas, pode-se perceber que algumas mantêm seu foco na produção / produto, enquanto outras se preocupam com o usuário e ainda há as que mantém seu foco em ambos, embora a prioridade seja limitada pela demanda. As metodologias brevemente descritas abaixo são hoje as mais populares no mercado.

\subsection{SCRUM}

Decididos a priorizar o software em funcionamento ante a documentação abrangente, a parceira com o cliente mais que negociação de contratos e a resposta às mudanças mais que seguir um plano rígido, especialistas em processos de desenvolvimento de software se reuniram e estabeleceram o "Manifesto Ágil”" (Beck, 2000 apud Rex Hartson; Pharda S. Pyla, 2012). Neste manifesto emergiram os seguintes objetivos: satisfazer os clientes com entregáveis rápidos e contínuos; entender que restrições de tempo e orçamento devam ser gerenciáveis e reconhecer que fazer alterações nos requisitos de desenvolvimento de softwares são norma inexorável. A metodologia Ágil valoriza:

- A pronta resposta às mudanças de acordo com o planejamento;

- A permissão e o incentivo às interações entre os indivíduos e ferramentas durante o processo;

- A compreensiva documentação de apoio e espera a contínua e necessária comunicação entre clientes e desenvolvedores;

- A flexibilidade dos clientes no tocante aos pontos estabelecidos no contrato.

Os princípios que balizam o Manifesto Ágil ${ }^{1}$ são a referência para o mercado. A Ágil engloba vários processos diferentes, dentre eles o Scrum, o Extreme Programming e o Kanban, por exemplo.

O Scrum, descrito e ilustrado abaixo (figura 3), foi selecionado como exemplo da metodologia Ágil pela sua popularidade.

1. www.agilemanifesto.com 


\section{SCRUM PROCESS}

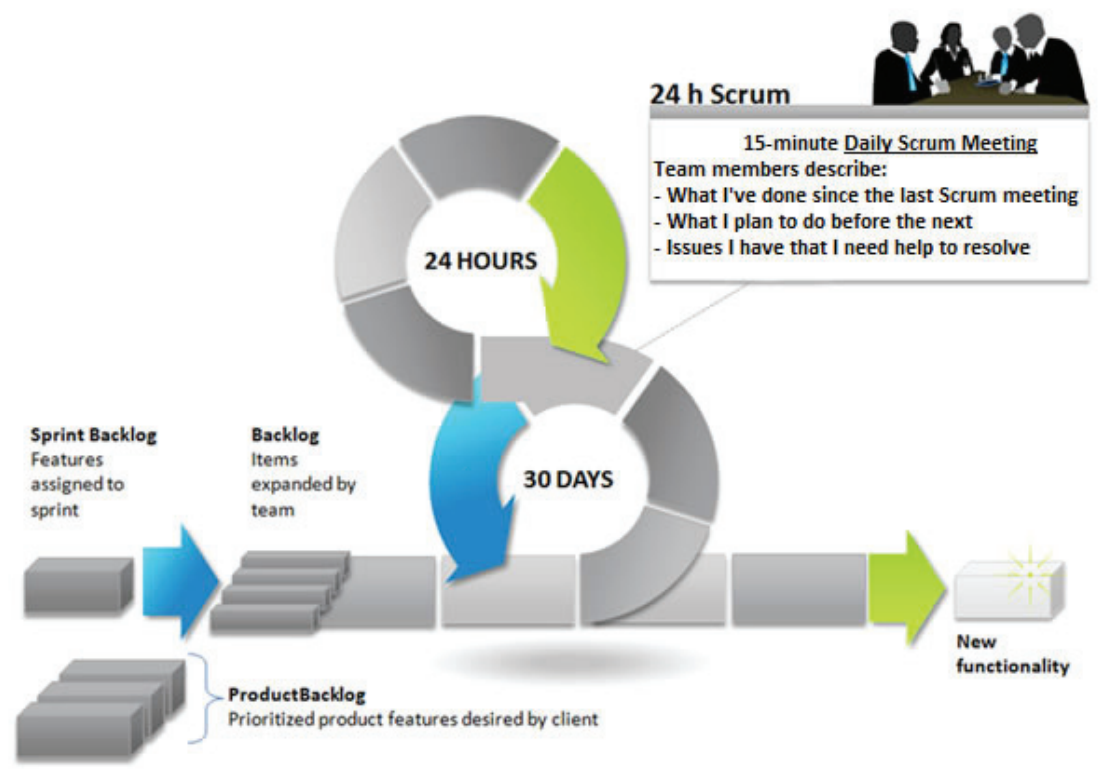

Figura 3: https://www.cprime.com/resources/what-is-agile-what-is-scrum/

(acesso em 11 de novembro de 2013 às 15h).

Em linhas gerais, a proposta dessa metodologia de desenvolvimento se organiza em uma série de iterações limitadas por espaços de tempo, que são os "ciclos" (também chamados de sprints). A frequente comunicação entre os membros da equipe é imperativa no Scrum, onde reuniões diárias de $15 \mathrm{~m}$ (daily standup) são feitas para compartilhar o que foi feito no dia anterior e decidir o que deve ser feito no mesmo dia. A ideia é facilitar ao máximo a comunicação efetiva entre os membros da equipe em nome do andamento produtivo do projeto. No começo dos ciclos são feitos os sprints mais longos do Scrum, com duração máxima de $8 \mathrm{~h}$, para planejamento dos sprints vindouros e dos entregáveis específicos de cada sprint subsequente.

Brown (2013) divide o Scrum em dois pólos: os membros da equipe e o backlog do produto. Os membros da equipe são o Scrum Master, o Product Owner e a equipe de desenvolvimento. O Scrum Master é o grande responsável pelo andamento do projeto, e deve remover qualquer obstáculo que se anteponha a esses objetivos. O Product Owner ( $P O$ ) deve definir as prioridades do trabalho, definir com a equipe as histórias dos usuários e representar a voz do usuário. A equipe de desenvolvimento por sua vez, deve fornecer feedback consensual sobre o escopo do trabalho como parte integrante desse processo. Alterações no projeto podem ser feitas, desde que de forma consensual. O backlog do produto é o repositório das histórias dos usuários, de quais tarefas serão necessárias para satisfazê-las e outros requisitos do projeto. 
O profissional de UX da equipe (se houver) geralmente tem pouco tempo para trabalhar no material antes que ele seja codificado. Embora para Brown (2013) a melhor opção seja incluir a voz do usuário no processo desde o início e semanalmente, a autora coloca que dedicar um sprint ou dois para sessões de teste de usabilidade possa ser uma opção factível. As maiores chances de sucesso estão baseadas na cultura, na dinâmica da equipe e do projeto e no quão essa equipe está preparada para os ciclos iterativos que envolvem essa abordagem.

Os autores Hartson e Pyla (2012) apontam que os métodos ágeis de desenvolvimento de softwares normalmente são caracterizados por optarem por uma dinâmica compartilhada, para que o feedback seja contínuo. Entretanto os autores colocam que no processo ágil não se menciona praticamente nada sobre o envolvimento do usuário durante o desenvolvimento do projeto. E ainda, os representantes de usuários não são usuários e não podem falar sobre a prática de outros. A participação do usuário é preterida em nome da agilidade do processo.

A ISO 9241210/2010 define a experiência do usuário (UX) como as percepções e respostas de um usuário resultantes do uso ou do uso antecipado de um produto, sistema ou serviço e lista três fatores que influenciam a $U X$ : o sistema, o usuário e o contexto de uso. Para a definição dos requisitos é fortemente recomendada a iteração da análise contextual dos usuários reais do produto. A proposta de Hartson e Pyla (2012) é inserir um analista de UX na SUFA (Small Up Front Analysis) para trabalhar junto ao cliente na etapa de contextualização e dar suporte na confecção e priorização das histórias.

\subsection{Design Thinking}

A essência do Design Thinking é explorar diferentes possibilidades ao priorizar os mapas mentais em lugar do pensamento linear. Como mapas mentais Brown (2010) entende o reconhecimento de padrões, o significado emocional antes do funcional, e a intuição, baseada na prototipagem e oriunda da abordagem criativa inerente à essa metodologia.

Processos impulsionados pelo Design Thinking partem da premissa de serem ilimitados (embora tenham metas claras e início, meio e fim bastante delimitados), neutros e iterativos e assumam a abordagem experimental: compartilhar processos, incentivar a abordagem coletiva de idéias e permitir que as equipes compartilhem aprendizados (Brown, 2010). O Design Thinking é veloz, indisciplinado, disruptivo e prega que longos relatórios, projeções orçamenárias e burocracia desnecessária podem comprometer a qualidade.

Para Brown (2010) o primeiro passo do Design Thinking é identificar as restrições do projeto sob três critérios, de forma bem equilibrada: 
- Praticabilidade: o funcionalmente possível;

- Viabilidade: o exequível e sustentável;

- Desejabilidade: o que faz sentido para as pessoas.

A partir da tríade, o Design Thinking faz uso da observação do comportamento das pessoas dentro do contexto para entender o mundo pelos olhos dos outros. Traduz essa reação em insights, que se tornarão produtos e serviços melhores para a vida alheia. O usuário é parte do processo e o processo parte do usuário. A ilustração abaixo (figura 4) sintetiza os passos fundamentais da metodologia:

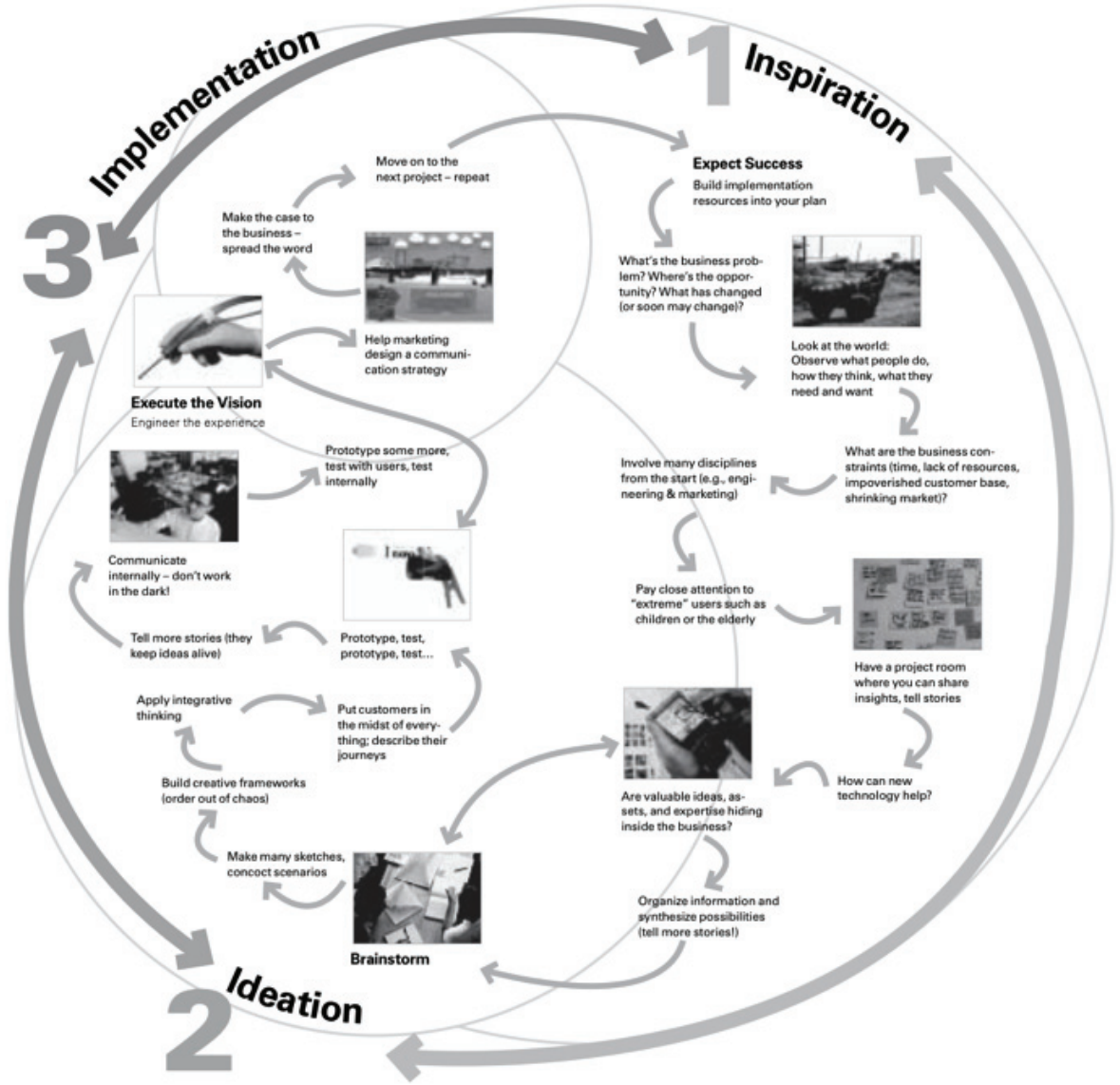

Figura 4. Ilustração da tríade fundamental do Design Thinking, publicada no artigo Design Thinking, de Tim Brown, em junho de 2008 no Harvard Business Review (www.hbr.org).

Outras técnicas utilizadas são o brainstorm, colocado como gerador de idéias e a prototipagem. A prototipagem é entendida por Brown (2010) como uma das mais importantes técnicas do Design Thinking - que a explica como 
$\mathrm{o}$ ato de transcender entre o físico e o abstrato sem compromisso com refinamentos técnicos, apenas o suficiente para decidir o que fazer. Essa metodologia promove a visibilidade simultânea de todos os materiais de pesquisa do projeto - fotos, storyboards, conceitos, protótipos - para incentivar a síntese criativa e a identificação de padrões de alternativas. Não raro é possível cobrir uma parede inteira de idéias promissoras escritas em papéis coloridos no decorrer de uma pesquisa profunda, como resultado de sessões de branstorming ou prototipagem, por exemplo.

\subsection{Ciclo de Engenharia da Usabilidade}

O Ciclo de Engenharia da Usabilidade (Mayhew apud Cybis, 2007) é cunhado nos princípios da ISO 13407/1999 (antiga ISO 9241210/2010) e tem por princípio a abordagem centrada no usuário para garantir a melhor experiência possível e um produto de qualidade. As técnicas propostas pelo Ciclo de Engenharia de Usabilidade devem ser apoiadas pela cultura da estrutura organizacional para que possam alcançar seus objetivos.

O ciclo deve ser iterativo e seguir os passos: análise, projeto (concepção) e testes, de forma a "identificar e refinar continuamente o conhecimento sobre o contexto de uso do sistema e as exigências em termos de usabilidade da interface" (Mayhew apud Cybis, 2007). A autora recomenda que o grau de refinamento dos protótipos evolua de acordo com o estágio do projeto e faz questão que o usuário seja envolvido desde muito cedo no processo, já que ninguém conhece melhor do que ele o sistema no contexto de seu trabalho. A equipe deve ser multidisciplinar e contar com a variedade de profissionais sugerida pela ISO 13407/1999: representantes de usuários primários e secundários, especialistas no domínio do trabalho, designers, analistas de usabilidade, engenheiros de software, programadores, técnicos em suporte e treinamento e responsáveis pelo marketing. Cybis (2007) ilustra o Ciclo de Engenharia da Usabilidade no esquema abaixo (figura 5): 


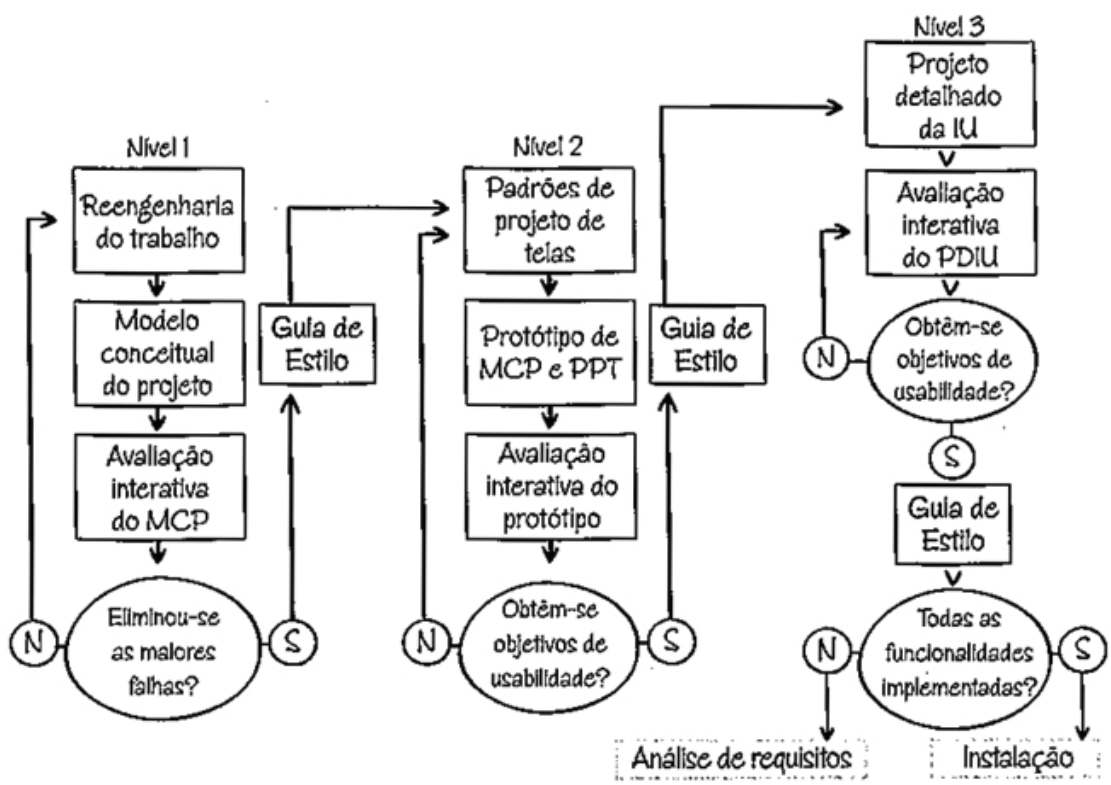

Figura 5. Etapas do ciclo de engenharia de Usabilidade idealizada por Déborah Mayhew esquematizada por Cybis (2007).

O Ciclo de Engenharia da Usabilidade (Mayhew apud Cybis, 2007) propõe que os ciclos do projeto apresentem três versões da mesma interface: modelo conceitual, padrão de telas e projeto detalhado. A metodologia prega que desenvolvedores e empresas (clientes dos desenvolvedores) devem investir em técnicas de planejamento e execução que envolvam o usuário em um dos seguintes papéis:

- Informativo: onde métodos e técnicas de pesquisa são aplicados para identificar o modelo mental dos usuários;

- Consultivo: quando o usuário se torna consultor do projeto;

- Participativo: quando o usuário passa a ter poder de decisão no projeto e torna-se co-autor das soluções da interface.

Essa metodologia prioriza o envolvimento do usuário, desde o início do projeto.

\subsection{Elements of User Interface}

A metodologia desenvolvida por Garrett (2011) considera que a experiência que o produto gera ao usuário final não pode ser negligenciada durante o processo de desenvolvimento, já que para o autor a experiência positiva do usuário com o produto é o real diferencial competitivo entre um produto e outro. O autor coloca que, para assegurar essa experiência positiva, é importante que 
alguém (não necessariamente um especialista em usabilidade) passe algum tempo refletindo sobre esses questões.

A metodologia consiste em cinco planos consecutivos: estratégia, escopo, estrutura, esqueleto e superfície que resultam no planejamento e execução de produtos com foco nos problemas dos usuários durante a interação e na forma de solução encontrada por eles. Abaixo confere-se a metodologia da concepção à completude e do plano mais abstrato ao mais concreto (figura 6):

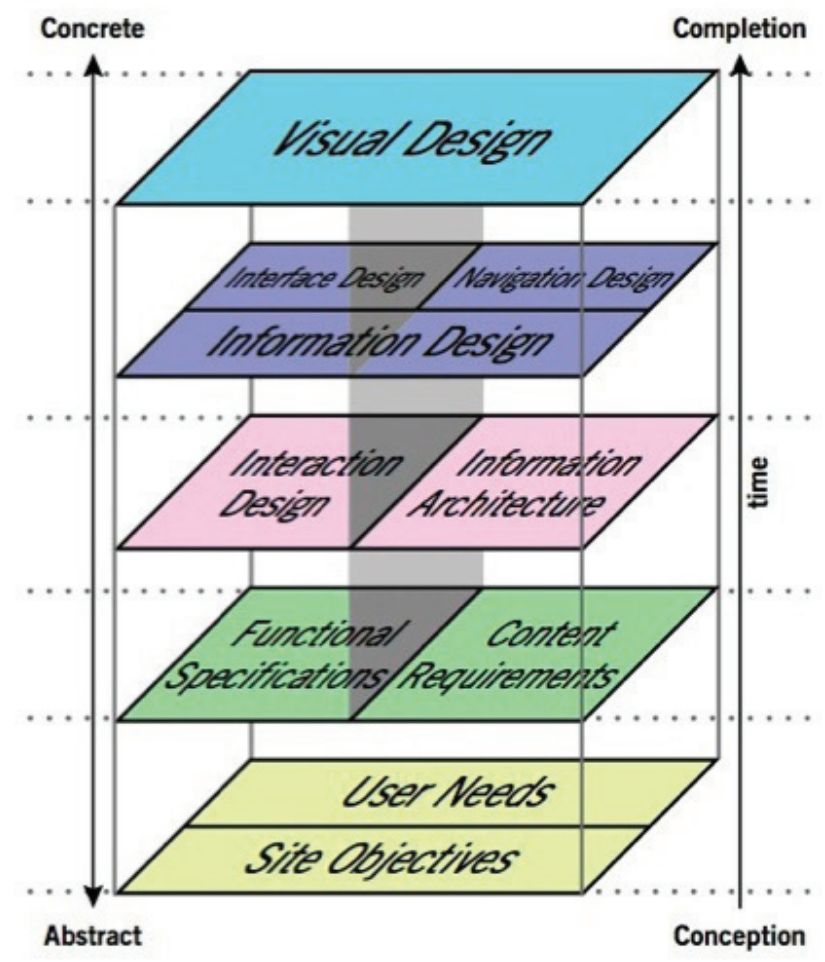

Figura 6. Metodologia proposta por Garret (2011)

A metodologia não se concentra na forma final do produto, ela considera o quanto o produto se encaixa na estratégia definida previamente e no quanto - e como - os objetivos do usuário são alcançados, ainda que o usuário não faça parte do processo.

\subsection{Lean UX}

A origem do termo Lean envolve uma filosofia de gestão que objetiva o máximo da produtividade através do mínimo de desperdício de tempo, recursos, processos, documentação e flexibilidade relativa entre clientes e equipe de desenvolvedores, para responder às mudanças e inovação contínuas, inerentes ao mercado e à própria tecnologia. 
A Lean UX, desenvolvida por Gothelf_(2013), fundamenta-se na junção da Lean Startup (Ries apud Gothelf,2013) e da metodologia Ágil e prima pela certificação de que o produto entregue é realmente o desejado / esperado pelo usuário. Essa certificação se dá através de pesquisas, iteração do processo e métricas de qualidade.

Somente é dedicada a ênfase necessária na documentação entregável, ou seja, o mínimo de informação para assegurar o início - ou a implementação do projeto. Essa prática encoraja rascunhos e protótipos de baixa fidelidade, enriquecidos por comentários e insights da equipe envolvida, que deve ser coesa e colaborativa para que os múltiplos talentos possam ser complementares. A filosofia Lean $U X$, focada na fase de design do projeto, encoraja o crescimento mútuo através da troca de conhecimento em busca da melhor experiência do usuário ao interagir com o produto. Segue abaixo a metodologia esquematizada (figura 7):

\section{Lean Cycles}

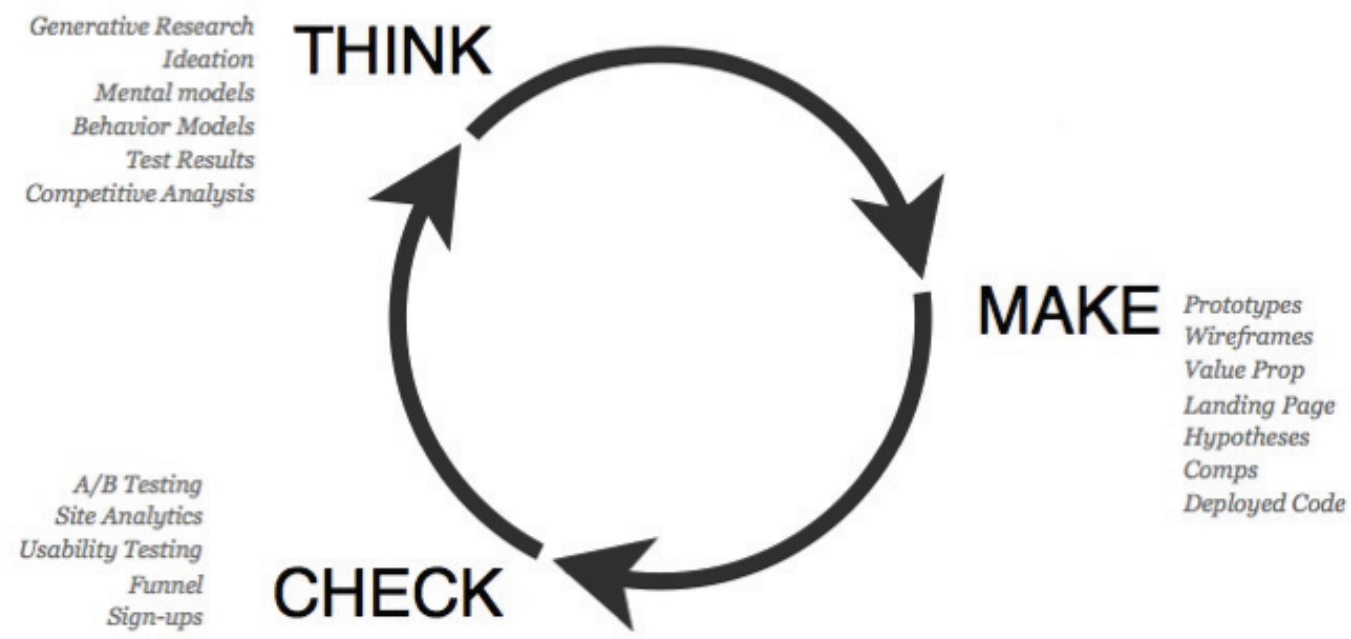

Figura 7. Ilustração da metodologia Lean $U X$, disponível em http://www.webgrrls.com/blog/wp-content/uploads/2011/08/leanuxcycle.jpg (acesso em 21 de novembro de 2013 às 15h)

A Lean UX incentiva a prática de benchmarkings e a criação de personas que representem os usuários do produto, embora nesse caso, a ordem dos passos para executar essa técnica tenha sido adaptada. Jeff Gothelf (2013) considera que perder muitas horas de entrevista (pesquisa de campo) antes de fazer pesquisas para validar as "crenças" da equipe seja desperdício e prega que as personas sejam desenvolvidas pela equipe reunida, onde prováveis 
usuários ilustram quem é o usuário real do produto e quais razões o levam a utilizá-lo. A metodologia não aponta o momento preciso da participação do usuário na etapa projetual, embora tenha por premissa que ele deva ser onipresente no processo.

\subsection{Rapid Contextual Design}

O Rapid Contextual Design se conecta com métodos ágeis e é um guia prático de procedimentos diários que objetiva que o menor tempo possível seja investido na burocracia do projeto, mas que o tempo se concentre nos benefícios finais. A metodologia molda-se a diferentes tipos de projetos ou de necessidades organizacionais, de forma que as técnicas sejam apropriadas ao caso. A Inquirição Contextual provém dicas importantes para extrair o melhor das técnicas aplicadas no projeto e guiar sessões de interpretação, bem como entrevistas em profundidade e storyboards, que se equiparam aos futuros cenários e outras técnicas aplicadas pelo Rapid Contextual Design, que prioriza a prototipagem. Segue esquema simplificado da Rapid Contextual Design (figura 8):

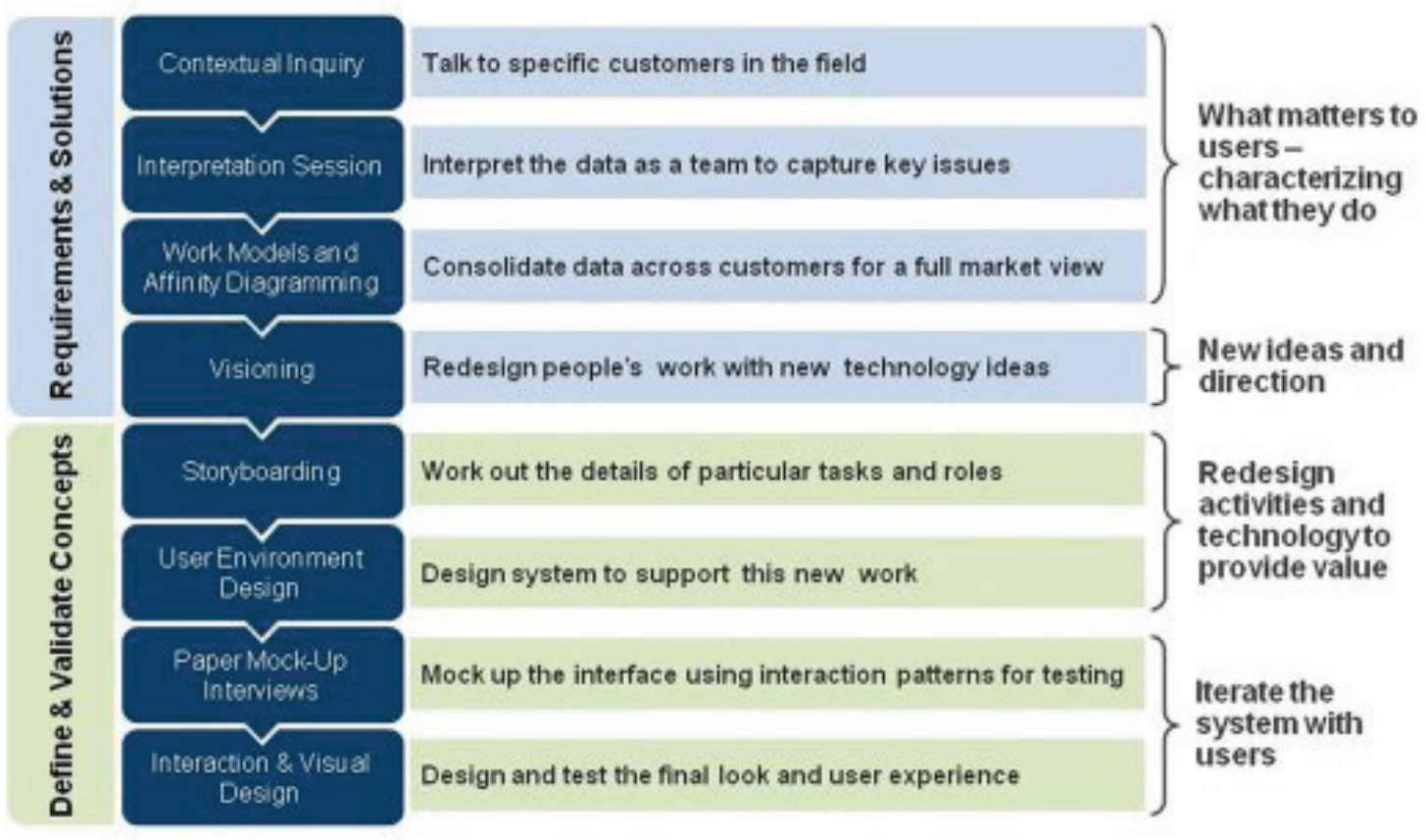

Figura 8. Etapas da Rapid Contextual Design esquematizadas. Disponível em http:// www.interaction-design.org/images/encyclopedia/contextual_design/Figure_1_CD_ process_illustrationSmaller.jpg (acesso em 21 de novembro de 2013 às 15h30m) 
A metodologia Rapid Contextual Design fornece exemplos e guias para incrementar a produtividade e ajudar a trazer o usuário - e todas as informações necessárias sobre ele - para os requisitos do design do sistema. Ainda que a inclusão do usuário no processo inevitavelmente reflita nos limites tempo $\mathrm{X}$ orçamento, a metodologia objetiva remover os argumentos das empresas ao apresentar melhor custo-benefício a longo prazo, com desenvolvimento rápido, mas certo de ter cumprido todas as etapas do processo, sem deixar de ter ouvido a voz do usuário.

\subsection{Goal-Directed Design}

Por volta do ano 2000, Alan Cooper formalizou com sua equipe algumas das técnicas de trabalho e treinamento já há muito praticadas, com o objetivo de fornecer bons resultados no tempo previsto. O método consiste nos seguintes itens:

- Princípios: São diretrizes criadas sob específicas circunstâncias para que sejam encontradas boas soluções que devem ser aplicadas a situação em questão e se certificar se realmente auxiliam o usuário a cumprir sua tarefa e se de fato minimizam a carga de trabalho do usuário;

- Padrões e processo: Nesse item são dispostos os passos e técnicas envolvidas no planejamento e condução da pesquisa em Design, fazendo uso do desenvolvimento de personas, cenários e requisitos para encontrar soluções iterativas de Design.

A amplitude do processo varia de acordo com as prioridades e as limitações de tempo e orçamento do projeto. São elas: Project planning, research, modeling, requirements definition, framework definition, detailed design e implementation suport, ilustradas (figura 9) abaixo e descritas detalhadamente a seguir: 


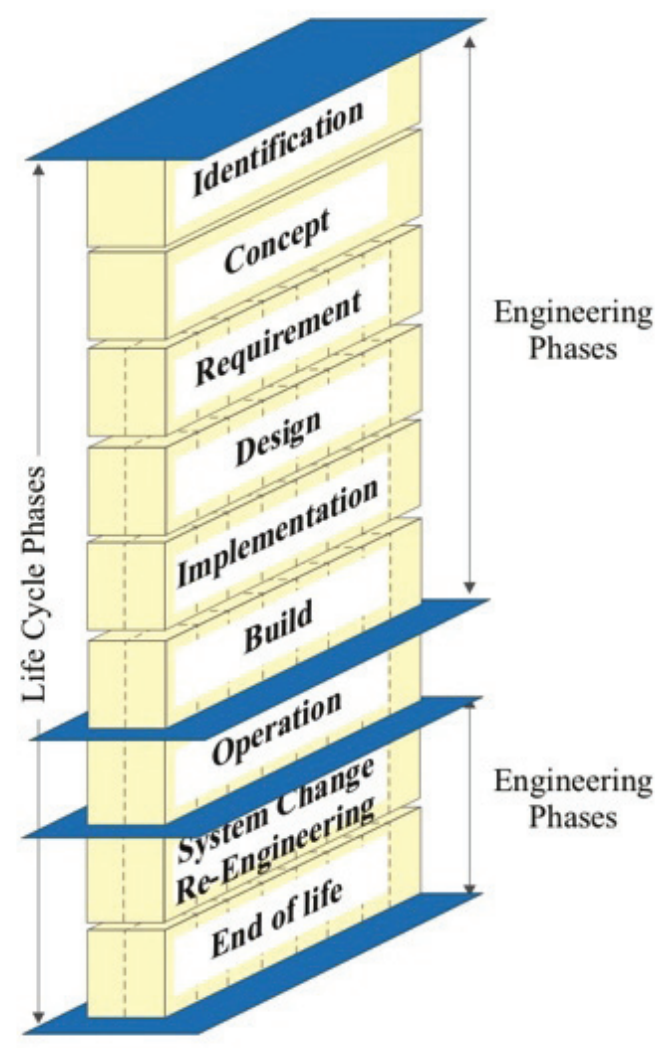

Figura 9. A metodologia Goal-Directed Design idealizada por Alan Cooper, disponível em http://upload.wikimedia.org/wikipedia/commons/f/f2/Enterprise_Engineering_and_ the_Life-Cycle_Concept.jpg (acesso em 21 de novembro de 2013 às 16h)

- Project planning se refere ao delineamento bruto do projeto, estrutura e resultados esperados;

- Research é composta de entrevistas com clientes (stakeholders) e é colocada em nome do consenso da equipe e da acelerção do processo em si;

- Modeling é a fase subsequente, onde são identificadas tendências e construídas personas. Cada uma das personas modeladas nesta fase representa um conjunto de comportamentos padrão e seus objetivos;

- Requirements definition é a fase posterior, na qual as personas e suas habilidades permitem a criação de cenários, que acabam por iluminar necessidades adicionais;

- Framework definition, fase na qual são exploradas múltiplas soluções e apresentadas ao cliente;

- Detailed design, que envolve dois passos: a equipe de designers provêm a maior quantidade de detalhes possível no primeiro rascunho do projeto, que é submetido então à apreciação dos especialistas em engenha- 
ria de software da equipe de desenvolvedores. Esta revisão será feita em busca de áreas que possam levantar questões ou outros receios. De acordo com a autora o primeiro rascunho detalhado é o momento ideal para a aplicação do teste de usabilidade;

- Implementation Suport, enriquecida com o bom relacionamento entre a equipe de designers e a dos especialistas da equipe de desenvolvedores.

\subsection{Wheel}

HARTSON e PYLA (2012) colocam que um grande percentual de projetos de desenvolvimento de produtos prioriza a entrega do produto ao invés das necessidades do usuário e considera essa prática comum no universo corporativo. A Wheel, metodologia proposta por eles, é um mapeamento iterativo das atividades possíveis para criar e refinar o design orientado pela qualidade da experiência do usuário, conforme figura (9) abaixo:

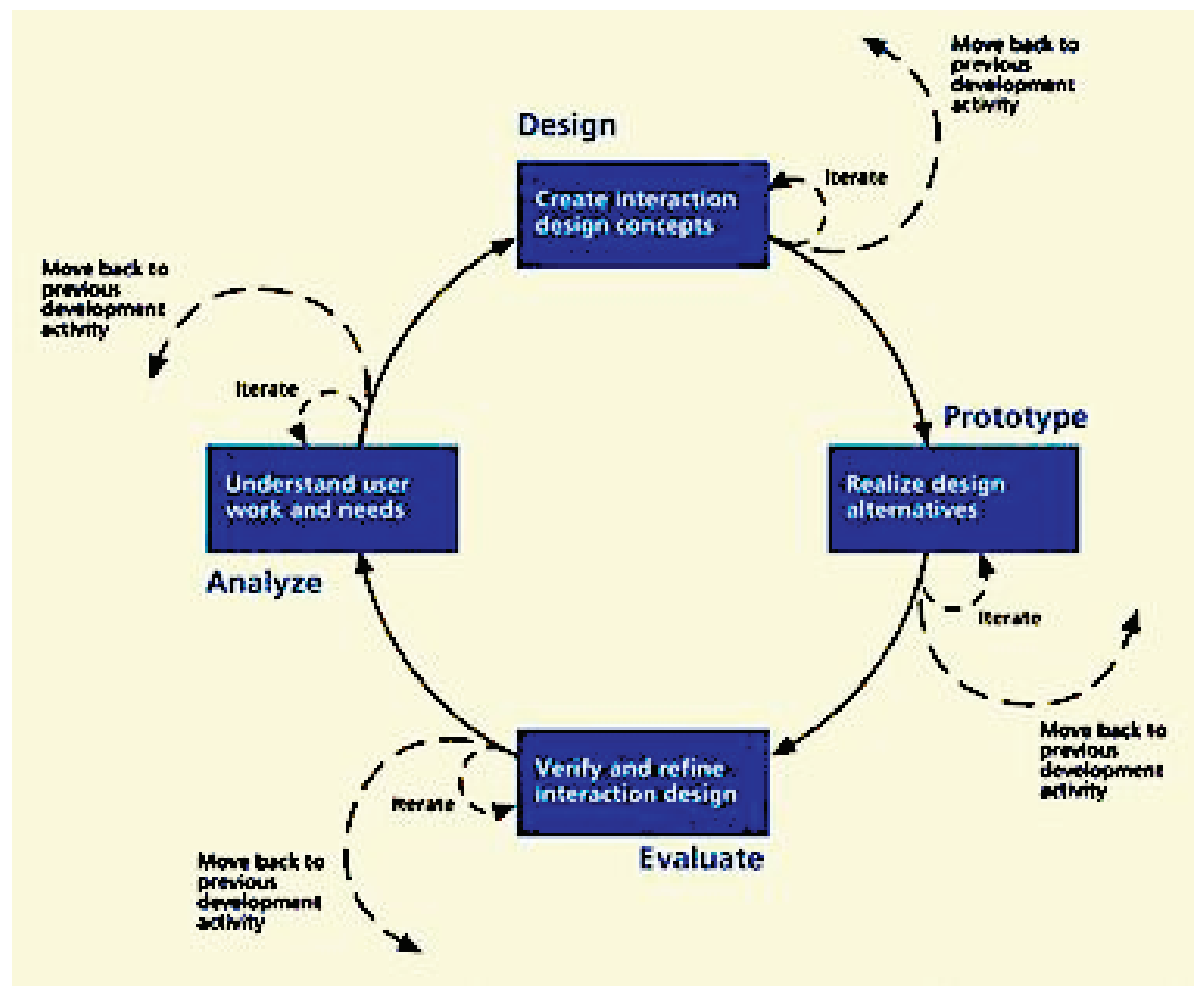

Figura 9. Metodologia Wheel, proposta por Hartson \& Pyla (2012) em seu UX Book.

Eles consideram que quando inseridos no seu contexto real, usuários são envolvidos no processo e podem ajudar a delinear o cenário de uso - e consequentemente levar a um redesign mais fiel às necessidades e expectativas do usuário.

A Wheel é baseada na adaptação e extensão de algumas metodologias de $U X$ e de softwares por anos, o ciclo básico envolve quatro atividades 
fundamentais de UX - análise, design, implementação e avaliação. Na fase de análise o autor coloca a inquirição contextual e a análise contextual como premissa para levantar os requisitos necessários, determinar os recursos, o comportamento e o "look and feel" do design de interação; na de design, ideias surgem baseadas em Design Thinking, brainstorming e scketchs, a ideação do Design deve representar o modelo mental dos usuários. A prototipagem é feita então, com diferentes propósitos e diferentes níveis de fidelidade e dá-se a avaliação, onde devem ser aplicados métodos que assegurem que o design promova o encontro entre a usabilidade e os objetivos do negócio.

O Wheel é centrado no senso de que os resultados de cada atividade devam ser avaliados de alguma forma, inspecionados, analisados e devolvidos aos clientes e usuários. A iteração de uma pequena parte do sub-processo está longe de ser custosa, pois ocorre cedo (quando as mudanças no design não são onerosas) e não causam grandes alterações no cronograma, já que podem ser feitas em paralelo a outras atividades previstas.

Dentre as maiores limitações de um projeto devem ser considerados especialmente o tempo e o orçamento, bem como a pessoa que tem poder de decisão, que deve ter intuitividade e pró-atividade aguçadas. Para que seja realmente efetivo, o gerente do projeto deve escolher as técnicas corretas no tempo e local ideais, especialmente falando de tempo e custos. Entre inúmeros fatores a se considerar na escolha do processo devem ser considerados: risco / tolerância; objetivos; recursos do projeto; tipo de design de sistema; cultura de desenvolvimento organizacional; estágio de progresso do projeto. Deve-se levar em conta que o nível de rigor ideal e as técnicas corretas a serem aplicadas são os fatores de maior influência na escolha do processo. Cabe ao gerente do projeto definir a equipe a ser envolvida em cada contexto e discussão, tendo em mente que sua composição não precisa ser estática durante todo o processo.

\subsection{Considerações sobre as metodologias}

A metodologia Ágil está em plena sintonia com o mercado, tem a entrega por prioridade e personifica o usuário através de representantes deles (Hartson e Pyla, 2012). A Elements of User Interface (Garrett, 2011) se concentra na experiência que o usuário terá com seu produto e apresenta etapas iterativas bem demarcadas. Assim como a Ágil, essa metodologia substitui o usuário real do produto por membros da equipe.

Embora personas sejam construídas em fases anteriores, na Goal-Directed Design o usuário só é inserido na prática na fase de detalhamento do design, ou seja, uma fase antes da implementação do projeto. Já a Rapid Contextual Design prega a inserção do usuário, mas não delimita as fases em que ele deve 
participar. A metodologia se molda ao projeto (e ao cliente) e prega que a relação custo / benefício investida na voz do usuário será positiva.

A Lean UX (Gothelf,2013) se preocupa com a inserção do usuário em busca de minimizar o risco de fracasso, mas se adequa às limitações de tempo e recursos impostas pelos responsáveis, e elimina tudo que possa se antepor ao andamento do projeto. A Wheel insere o usuário nas quatro fases e coloca grande parte da responsabilidade nas mãos do gerente do projeto, que deve prever as atividades de forma que o orçamento e tempo previstos sejam respeitados.

O Ciclo de Engenharia da Usabilidade (Mayhew apud Cybis, 2007) e o Design Thinking (Brown, 2010) elevam a participação dos usuários como imperativa: além do Ciclo de Engenharia da Usabilidade (Mayhew apud Cybis, 2007) ser embasado por uma equipe multidisciplinar, não só prevê a participação ativa do usuário real como, em alguns casos, pode promovê-lo a co-autor do projeto. O Design Thinking (Brown, 2010) conta com uma equipe bem qualificada e diversificada e tem por prioridade a participação do usuário para validar seus projetos: observa, analisa, transforma ideias em produtos e os arremata com o feedback do usuário. Essa metodologia soma design e inovação à experiência do usuário. Ambas deixam claro que a participação do usuário deve iniciar junto com o projeto.

Em busca de resultados que satisfaçam a clientela, empresas desenvolvedoras fazem uso de metodologias existentes, mas pergunta-se até que ponto os princípios do Design Centrado no Usuário são respeitados em nome do usuário final do produto, ou seja, se esses são considerados na prática.

\section{Usuário, o personagem principal.}

As interfaces digitais são fascinantes e devem propor experiências gratificantes aos usuários, o que faz com que a boa usabilidade seja imperativa neste caso. A definição da ISO 9241-210/2010 esclarece que a usabilidade não deve ser uma propriedade isolada do produto, pois ela irá depender da consideração do usuário, das metas que esse objetiva alcançar e do contexto de uso no qual ele estiver inserido. A partir desta afirmação cabe colocar a experiência do usuário de sistemas interativos, em especial os mobiles - e em todos os recursos que eles oferecem - como relevante, num cenário moderno no qual a grande fatia da população está inserida, já que o conceito de usabilidade trata da relação produto e usuário dentro do contexto de uso. A participação ativa do usuário, característica das boas metodologias, deve fazer parte da cultura da empresa desenvolvedora e ser preocupação inerente a pesquisas desse tipo.

A questão é que os ambientes de desenvolvimento são submetidos a cronogramas e orçamentos limitados e demandam maneiras mais efetivas de 
adaptar os processos de UX às pressões do mundo corporativo. Clientes ansiosos, em especial os que buscam produtos comerciais demandam entregas rápidas. Não raro, as equipes de desenvolvimento precisam pular etapas do projeto e utilizar técnicas rápidas para satisfazer a demanda. Este cenário faz com que o lado dedicado à $U X$ (experiência do usuário) no projeto se adeque às restrições impostas pela equipe de desenvolvimento de software.

Desenvolvedores costumam ser centrados em suas próprias habilidades e conhecimentos e acabam por subestimar as diferenças entre seu modelo mental e o do usuário. Talvez a maior surpresa da equipe desenvolvedora ao participar diretamente da pesquisa com o usuário seja perceber o quanto operações aparentemente simples possam ser difíceis, senão intransponíveis, para o usuário. Esse ponto ilumina a necessidade de que, além de ouvir a opinião importante dos especialistas, a equipe se envolva diretamente com o usuário.

As melhores informações, as realmente úteis, podem não ser as extraídas de perguntas diretas. Muitos usuários agem de forma diferente de seu discurso, mesmo que inconscientemente. A conduta adequada é, antes de tudo, abstrair as vias indiretas de informação sobre o usuário, não priorizar a codificação e usar técnicas adequadas, ou seja, as técnicas que proporcionem a melhor visibilidade possível do modelo mental do usuário dentro do contexto em questão. De acordo com os interesses dos desenvolvedores, existe ainda a possibilidade desse usuário tomar uma postura participativa, quando pode rever, concordar ou discordar das soluções de design que a equipe tenha encontrado antes que uma única linha de código tenha sido escrita, economizando tempo e subsídios. Deverão ser feitas quantas iterações do projeto forem necessárias até que a satisfação seja a ideal, mas essa etapa terá sido muito adiantada se a voz do usuário tiver sido ouvida desde o início.

Mesmo que exista alguma preocupação em torno dos ruídos ou entraves que a participação do usuário possa trazer, é importante que a equipe desenvolvedora perceba os ganhos que a compreensão cognitiva e emocional dos envolvidos podem trazer ao projeto final. Os desenvolvedores são os grandes responsáveis pelo equilíbrio entre os interesses do cliente e os do usuário e se a equipe desenvolvedora interagir mais com os usuários reais do produto, a relação dela com os métodos de pesquisa será cada vez mais clara - e objetiva. Pode ser que a interação com o usuário não assegure todos os requisitos do projeto, mas certamente muitas das questões de design serão definidas a partir dela. Quanto mais prematuro for o envolvimento dele, melhor.

Eventualmente a premência competitiva do mercado pode trazer obstáculos para a prática da interação direta com o usuário, mas o argumento sólido dos ganhos à médio e longo prazo são indiscutíveis. 


\section{Considerações Finais}

O cenário de proporções substanciais do mercado de smartphones aponta para a relevância deles no cotidiano dos usuários. Os aplicativos para mobiles acompanham esse crescimento e proliferam nas telas dos smartphones de forma exponencial, o que ilumina a necessidade das empresas desenvolvedoras de colocar o apps no mercado e acompanhar a concorrência, faz com que os cronogramas sejam cada vez mais limitados e aumenta substancialmente o número de versões e updates. Esta realidade precisa ser adaptada aos processos de UX, ponderando-se a agilidade de métodos rápidos, o custo benefício e principalmente a ISO 9241210/2010, que deve ser complementar à metodologia de produção escolhida, de forma que todos os envolvidos possam ser beneficiados. Os gerentes do projeto devem prever o tempo necessário para que a experiência do usuário seja colocada explicitamente no cronograma, pois esse investimento se pagará com generosos dividendos, seja para o cliente, a empresa desenvolvedora ou o próprio usuário.

Em busca de resultados que satisfaçam a clientela, empresas desenvolvedoras de aplicativos para mobiles fazem uso de metodologias existentes, mas pergunta-se até que ponto os princípios do Design Centrado no Usuário são respeitados em nome do usuário final do produto, ou seja, se esses são considerados na prática. Scrum, Design Thinking e Lean UX são algumas das metodologias aqui descritas e atualmente as mais utilizadas pelas empresas, mas outras metodologias - ou uma reedição dessas - podem se tornar mais eficazes na questão do desenvolvimento de um produto de qualidade para um usuário específico. A percepção empírica suscita as seguintes questões:

- Existe uma fase específica para a participação do usuário no processo?

- As metodologias atendem os requisitos do mercado (clientes/desenvolvedores), mas não consideram o usuário de acordo com os princípios do Design Centrado no Usuário?

- Os parâmetros da ISO 9241-210/2010 são desconsiderados e / ou desconhecidos na prática?

- Quais os consequentes prejuízos dessa desconsideração / desconhecimento para os usuários?

- Falta uma metodologia que proporcione o melhor custo / benefício para ambas as partes (a empresa - e toda a agilidade de desenvolvimento que o mercado espera dela - e o usuário)?

A partir das suspeitas elencadas acima, serão exaustivamente investigados e tratados os dados em busca das respostas e da consequente satisfação de toda cadeia produtiva envolvida no projeto. 
Nada mais coerente com as premissas da Ergonomia e da IHC que traduzir a linguagem homem/máquina e adequar cada vez mais os sistemas às necessidades dos usuários, tornando o suporte transparente aos olhos dele e a interação, o mais natural e intuitiva possível. Fabricantes de smartphones, desenvolvedores de aplicativos para mobiles e seus clientes, profissionais de ergonomia e IHC, e terceiros envolvidos direta ou indiretamente no projeto serão recompensados ao trazer o usuário à cena. Mesmo que o cronograma tenha que ser revisto, esse ajuste será compensado em longo prazo, com melhores resultados e menor necessidade de fazer atualizações, que acabam por incrementar os custos. O grande beneficiado será o protagonista, o usuário final de sistemas interativos para mobiles, os apps.

O objetivo primo de uma pesquisa com foco nas metodologias descritas é propor uma metodologia exequível, rentável e adequada aos princípios do Design Centrado no Usuário, que tenha a plasticidade necessária para ser aplicada em diferentes demandas de empresas e/ou projetos. Os resultados desejados são:

- Revelar importantes recomendações e sugestões aos desenvolvedores de softwares e suas equipes no intuito de aprimorar a usabilidade de seus produtos sem acrescer custos ao orçamento destas empresas;

- Desencadear recomendações e sugestões que podem revelar uma nova metodologia, calcada em critérios ergonômicos e idealizada para o bem comum;

- Auxiliar e orientar aos profissionais envolvidos na cadeia produtiva e pesquisadores interessados em Ergonomia e Usabilidade;

- E, em última análise, incentivar as empresas desenvolvedoras a utilizarem os parâmetros da ISO 9241-210 na prática, em todas as etapas do desenvolvimento de aplicativos para mobiles e os consequentes ganhos para todos os pontos da cadeia produtiva.

Com o mercado de proporções tão relevantes como o exposto, responsáveis pelo desenvolvimento desses aplicativos tem inerente necessidade de adaptar seu processo às realidades de $U X$ à agilidade que as limitações do projeto impõem. Os resultados de estudos com esse foco poderão fazer com que as recomendações e os princípios do Design Centrado no Usuário sejam postos em prática pelas empresas desenvolvedoras de aplicativos a despeito das restrições orçamentárias impostas pelas contratantes e que o maior beneficiário seja sempre o usuário, seguido da viabilidade do projeto. 


\section{Referências Bibliográficas}

BROWN, Tim. Design Thinking: Uma poderosa metodologia para decretar o fim das velhas idéias $-3^{\mathrm{a}}$ Ed. Tradução: Cristina Yamagami. Rio de Janeiro: Campus - Elsevier, 2010.

BROWN, Diana; Agile User Experience Design: A Practitoner's Guide to Making it Work. Waltham: Morgan Kaufmann, 2013.

CYBIS, Walter; BETIOL, Adriana H. e FAUST, Richard. Ergonomia e Usabilidade: Conhecimentos, Métodos e Aplicações. São Paulo: Novatec Ed., 2007.

GARRET, James J.; The Elements of User Experience: User centered design for the web and beyond. Berkeley: New Riders, 2011.

GOTHELF, Jeff; SEIDEN, Josh. Lean UX - Applying Lean Principles to Improve User Experience. Sebastopol: O”Reilly, 2013.

HARTSON, Rex; PYLA, Pardha S.; The UX Book: Process and guidelines for ensuring a quality user experience. Waltham, MA / US: Elsevier, 2012.

HOLTZBLATT, Karen; WENDELL, Jessamyn B.; WOOD, Shelley. Rapid Contextual Design: A How-to Guide to Key Techniques for User-Centered Design (Interactive Technologies). San Diego: Morgan Kaufmann, 2004.

INTERNATIONAL STANDARD ORGANIZATION. Human-Centred Design Process for Interactive Systems (13407). Génève: ISO, 1999.

INTERNATIONAL STANDARD ORGANIZATION. Ergonomics of humansystem interaction Part 210: Human-centred design for interactive systems (9241-210). Génève: ISO, 2010.

LINDSTROM, Martin; Brand Sense: Sensory Secrets Behind the Stuff we Buy. New York: Free Press, 2010.

MAYHEW, Deborah.; The Usability Engineering Lifecycle: a practitioner's handbook for user interface design. San Diego: Morgan Kaufmann, 1999. 
MELCHER, Christiane. Dissertação mestrado. Proposta metodológica para avaliações otimizadas de usabilidade em websites desenvolvidos com um método ágil: Um estudo de caso. Rio de Janeiro: PUC, 2012.

GOODWIN, Kim. Designing for Digital Age - How to Create Human-Centered Products and Services. Indiana: Wiley Publishing Inc., 2009.

RIES, Eric. The Lean StartUp: How today's entrepreneurs use continous innovation to create radically successful businesses. New York: Crown, 2011.

SKELDON, Paul. M Commerce: Boost your business with the power of mobile commerce. Richmond: Crimson, 2011.

WROBLEWSKI, Luke. Mobile First. New York: Zeldman, 2011.

\section{Agradecimentos}

À PUC, instituição à qual me orgulho e agradeço diariamente à Deus por fazer parte. 
Recebido em: 10/06/2013

Aceito em: 01/10/2013

\section{Como citar}

CHAMMAS, Adriana; QUARESMA, Manuela; MONT'ALVÃO, Cláudia. Um enfoque ergonômico sobre a metodologia de design de interfaces digitais para dispositivos móveis. Arcos Design. Rio de Janeiro: PPD ESDI - UERJ. Volume 7 Número 2 Dezembro 2013. pp. 145-171. Disponível em: [http://www.e-publicacoes. uerj.br/index.php/arcosdesign]

\section{DOI}

10.12957/arcosdesign.2013.12188

\section{(c) (1) (2)}

A Revista Arcos Design está licenciada sob uma licença Creative Commons Atribuição - Não Comercial - Compartilha Igual 3.0 Não Adaptada. 